\title{
Different Effects of the RNASEL R462Q Mutation on the Risk of Developing Prostate and Cervical Cancer in Latin American Subjects: A Meta-Analysis
}

Porchia $\mathrm{ML}^{1}$, Meda $\mathrm{E}^{1}$, Zepeda $\mathrm{RC}^{1,2}$, Orduña-Salazar $\mathrm{AA}^{3}$, Juárez-Salazar $\mathbf{G}^{3}$, González-Mejia $\mathrm{ME}^{3}$ and $\mathrm{Aguirre} \mathbf{G}^{\text {* }}$

${ }^{1}$ Laboratorio de Genética y Biología Molecular, Hakken Enterprise S.A. de C.V, México

${ }^{2}$ Centro de Investigaciones Biomédicas, Universidad Veracruzana, México

${ }^{3}$ Facultad de Medicina, Benemérita Universidad Autónoma de Puebla, México

*Corresponding Author: Aguirre G, Laboratorio de Genética y Biología Molecular, Hakken Enterprise S.A. de C.V. Río Conchos No. 216 Vista Hermosa, 62790 , Cuernavaca, Morelos, México, Tel: 01551227 2200; E-mail: gisi@hakkenenterprise.com

Received date: July 02, 2015; Accepted date: August 14, 2015; Published date: August 19, 2015

Copyright: @2015 Porchia ML. This is an open-access article distributed under the terms of the Creative Commons Attribution License, which permits unrestricted use, distribution, and reproduction in any medium, provided the original author and source are credited.

\section{Abstract}

Background: Prostate and cervical tissues are highly susceptible to carcinogenesis. Furthermore, some reports suggest that alterations in RNASEL have been associated with augmented risk of developing cancer, specifically the arginine to glutamine mutation at position 462 (R462Q). However, with conflicting results of the R462Q mutation on cancer risk, our goal was to determine what effect this mutation had on prostate and cervical cancers in Latin Americans.

Methods: PubMed, EBSCO, SCOUPS, Wiley and OVID databases, and study bibliographies were systematically searched for case-control studies that examined for the R462Q mutation until June 2015. Odds ratios (ORs) and $95 \% \mathrm{Cl}$ were calculated from the genotype data. The pooled ORs were obtained by the Peto method for the heterozygous, the homozygous, the dominant, the recessive, and the allelic genetic models. Heterogeneity was assessed by the Q-test and 12-test. Publication bias was assessed by the Begg and Mazumdar's test and the Egger's test. The sensitivity was determined by reevaluation of the pooled OR after removal of one study.

Results: From the 153 retrieved studies, four studies met the inclusion criteria ( $n=808$ subjects). The pooled results did not indicate any association between $\mathrm{R} 462 \mathrm{Q}$ and overall cancer risk for any of the genetic model assessed. However, when stratified by type of cancer, the homozygous and the recessive genetic models demonstrated a significant association between prostate cancer $(O R=2.26,95 \% \mathrm{Cl}=1.15-4.44, p<0.05$ and $O R=2.18$, $95 \% \mathrm{Cl}=1.12-4.23, \mathrm{p}<0.05$, respectively) and cervical cancer $(\mathrm{OR}=0.32,95 \% \mathrm{Cl}=0.13-0.74, \mathrm{p}<0.01$ and $\mathrm{OR}=0.35$, $95 \% \mathrm{Cl}=0.16-0.77, \mathrm{p}<0.01$, respectively). Furthermore, the risk associated with this mutation for prostate cancer and cervical cancer was different $(p<0.01)$.

Conclusion: Here we denote, for Latin Americans, the different effects the RNASEL R462Q mutation has for prostate (increased risk) and cervical (decreased risk) cancers.

Keywords: Arg462Gln, Ribonuclease L, Genetic biomarkers, Prediction, Viral-induced cancer, Polymorphism, Hispanic ethnicity

\section{Introduction}

Prostate and cervical cancers are one of the most common causes of cancer-related deaths worldwide, with 2.7 and 2.4 deaths per 100,000 per year in men and women, respectively $[1,2]$. However, the prevalence and mortality rates for these cancers has demonstrated a marked geographic variation [2]. For Latin Americans, the incidence was 15,400 and 76,000 for prostate and cervical cancers, respectively $[2,3]$. The majority of the population in Latin American countries shares many ethnic and genetic characteristics that are different from other European, Asian, and North American countries [4-6]. However, with few reports focusing on Latin American countries, there is a current need to determine the importance of certain factors that elevate the risk of developing cancer.

During the past years, numerous studies have shown that prostate and cervical cancers are viral-induced related cancers [7-9]. Therefore, examining components of the anti-viral pathway may aid in understanding how certain proteins factor in carcinogenesis. One gene of interest, expressed in both prostate and cervical tissue, is the ribonuclease L (RNASEL), an enzyme in the interferon-induced antiviral 2-5A pathway [10-12]. Mutations in the RNASEL gene lead to reduced enzymatic activity and abrogate its tumor suppressor role $[13,14]$. One of the most studied RNASEL variant is the $1385 \mathrm{G} \rightarrow \mathrm{A}$ polymorphism, which results in the amino-acid substitution from arginine to glutamine at position 462 (R462Q), whose potential impact on prostate and cervical cancer risk remains controversial $[15,16]$.

The R462Q mutation, which is located in the kinase-like domain, is able to bind 2-5A but with diminished capability to form its active conformation [17]. The QQ genotype has shown to reduce its enzymatic activity by 3 -fold and unable to induce apoptosis $[17,18]$. For prostate cancer, the R462Q mutation has an ethnic component. For patients from Germany and Sweden, there is no association $[19,20]$; however, there was a significant association for patients of Finnish or African descent for increase prostate cancer risk [21,22]. For cervical cancer, there are few reports to determine if there is an 
Citation: Porchia ML, Meda E1, Zepeda RC, Orduña-Salazar AA, Juárez-Salazar G, González-Mejia ME, et al. (2015) Different Effects of the RNASEL R462Q Mutation on the Risk of Developing Prostate and Cervical Cancer in Latin American Subjects: A Meta-Analysis. J Carcinog Mutagen 6: 234. doi:10.4172/2157-2518.1000234

Page 2 of 6

ethnic component. A recent report suggested that $13 \%$ of all prostate cancer cases are associated with the R462Q mutation [18], on the other hand, with cervical cancer, the data on its prevalence is lacking. The effect of the R462Q mutation on cervical cancer has been posited to be "protective" [16], whereas with prostate cancer the effect in mainly associated with cancer development [23]. In Latinos, no direct comparison of the effect of the R462Q mutation on prostate and cervical cancer has been established; therefore, we conducted a metaanalysis to deduce and compare the impact of the R462Q mutation on prostate and cervical cancer risk in Latin Americans.

\section{Methods and Materials}

\section{Publication search}

PubMed, OVID, Wiley, SCOPUS and EBSCO databases were searched for all case-control studies that investigated the association between RNASEL (R462Q) and cancer. The following keywords and related index terms were used: "RNASEL", "mutation or polymorphism", "cancer or carcinogenesis" and terms specific for prostate and cervical cancers for any studies published up to June 10, 2015. Only studies published in English, Spanish, and Portuguese were reviewed. The titles and abstract were examined, and studies that were not eligible for this meta-analysis were eliminated. The complied publications' references were hand searched. Three authors determined if each study was to be included. All studies had to meet the following criteria: case-controls studies that focused on examining the association of the mutation in human subjects with prostate or cervical cancer. Afterwards, only studies focusing on Latin American countries or their descendants were considered. Non-human studies, reviews, prospective studies, or studies with insufficient information were excluded.

\section{Data extraction}

Two of the authors extracted all data independently. If there was a disagreement, another author assessed the study in question. If a single sample was believed to be use in multiple reports, the reports were assessed to determine which one was the most representative and that data was used, or the corresponding author was contacted to resolve the issue. The data collected were first author's name, year of publication, geographical location, type of cancer, genotyping method, source of control, distribution of genotypes among the cases and controls, as well as the total number of subjects.

\section{Statistical analysis}

The Hardy-Weinberg Equilibrium (HWE) was determined by the $\Psi 2$-test for the controls for each study. The crude odds ratio (OR) and the $95 \%$ confidence interval $(95 \% \mathrm{CI})$ were calculated for each study and used to assess the level of association between the mutation and cancer susceptibility. The pooled ORs were assessed for the following genetic models: homozygous (QQ versus RR), heterozygous (RQ versus $R R$ ), dominant ( $Q Q+R Q$ versus $R R$ ), recessive ( $Q Q$ versus $R Q$ $+R R$ ), and allelic ( $Q$ versus $R$ ). The analyses were stratified by type of cancer. To determine the pooled OR, the Peto method was used [24]. Heterogeneity was determined using the $\Psi 2$-based Q-test and its degree was assessed by the I2 value (inconsistency index). The stability and sensitivity of the results were assessed by removing one study and re-calculating the pooled OR. Publication bias was evaluated by the Begg and Mazumdar adjusted rank correlation asymmetry test (Kendall's tau) and the Egger regression asymmetry test [25,26]. The $\Psi 2$-test was used to determine differences between groups. Statistical analyses were performed using either Review Manager (RevMan) v5.3. (Copenhagen, DK) and StatDirect Statistical Software version 3.0.147 (Cheshire, UK). P-values $<0.05$ (two-sided) were considered statistically significant.

\section{Results}

\section{Characteristics of the studies}

One-hundred fifty-three studies were retrieved from searching the multiple databases and from reviewing the study's bibliographies. Ninety-seven studies were exclude because they did not focused on cancer and RNASEL, focused on animals or cell lines, or were not a research article. The remaining 56 studies were evaluated extensively. Six studies did not focus on the R462Q mutation, two lacked sufficient information, and twelve were not case-control studies, therefore they were excluded. From the remaining 36 studies, only four utilized subjects from Latin America or their descendants (Figure 1).

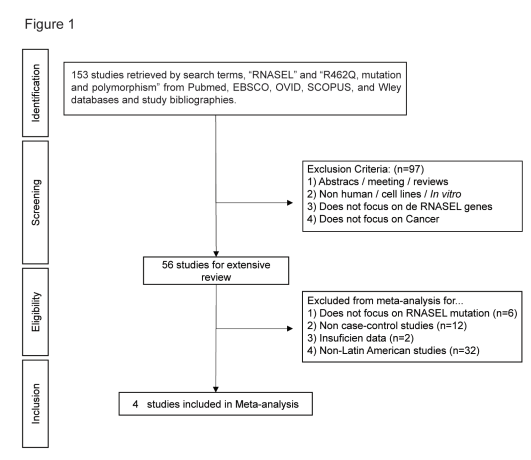

Figure 1: Meta-analysis selection diagram

Therefore, our sample consisted of 808 subjects (controls $=420$ and cases $=388$ ). Detailed characteristics of these studies are listed in Table 1.

\begin{tabular}{|c|c|c|c|c|c|c|c|c|c|c|c|c|}
\hline \multirow[t]{2}{*}{ First Author } & \multirow[t]{2}{*}{ Year } & \multirow[t]{2}{*}{ Country } & \multirow[t]{2}{*}{ Cancer } & \multirow{2}{*}{$\begin{array}{l}\text { Genotyping } \\
\text { Methods }\end{array}$} & \multirow{2}{*}{$\begin{array}{l}\text { Source of } \\
\text { controls }\end{array}$} & \multirow[t]{2}{*}{ Groups } & \multicolumn{3}{|c|}{ R462Q Genotypes } & \multirow[t]{2}{*}{ Total } & \multirow[t]{2}{*}{ HWE a } & \multirow[t]{2}{*}{ Ref } \\
\hline & & & & & & & $\mathrm{RR}$ & $R Q$ & $\mathrm{QQ}$ & & & \\
\hline \multirow[t]{2}{*}{ Barbison } & 2011 & Argentina & Cervical & Pyrosequencing & $\mathrm{HB}$ & Controls & 44 & 57 & 22 & 123 & 0.64 & [22] \\
\hline & & & & & & Cases & 44 & 48 & 6 & 98 & & \\
\hline
\end{tabular}


Citation: Porchia ML, Meda E1, Zepeda RC, Orduña-Salazar AA, Juárez-Salazar G, González-Mejia ME, et al. (2015) Different Effects of the RNASEL R462Q Mutation on the Risk of Developing Prostate and Cervical Cancer in Latin American Subjects: A Meta-Analysis. J Carcinog Mutagen 6: 234. doi:10.4172/2157-2518.1000234

Page 3 of 6

\begin{tabular}{|l|l|l|l|l|l|l|l|l|l|l|l|l|}
\hline Beuten & 2010 & USA & Prostate & Taqman Assay & HB & Controls & 126 & 91 & 7 & 224 & 0.05 & {$[24]$} \\
\hline & & & & & Cases & 75 & 64 & 17 & 156 & \\
\hline $\begin{array}{l}\text { San } \\
\text { Francisco }\end{array}$ & 2014 & Chile & Prostate & Taqman Assay & PB & Controls & 11 & 6 & 4 & 21 & 0.11 & {$[12]$} \\
\hline & & & & & Cases & 43 & 31 & 9 & 83 & & \\
\hline Zabala & 2009 & Venezuela & Prostate & PCR-ASA & HB & Controls & 34 & 16 & 2 & 52 & 0.95 & {$[23]$} \\
\hline & & & & & Cases & 37 & 10 & 4 & 51 & & \\
\hline $\begin{array}{l}\text { Abbreviation: HB: Hospital Base; PB: Population Based; PCR-ASA: Polymerase-Chain Reaction Allelic Specific Amplification; HWE: Hardy-Weinberg Equilibrium. } \\
\text { The Hardy-Weinberg Equilibrium was calculated by the 2-test, values greater than 0.05 are consider to agree }\end{array}$
\end{tabular}

Table 1: Characteristics of each study included in the meta-analysis.

\begin{tabular}{|c|c|c|c|c|c|c|c|c|c|}
\hline \multirow[t]{2}{*}{ Genetic Model } & \multirow[t]{2}{*}{ Cancer } & \multicolumn{2}{|c|}{ Heterogeneity } & \multicolumn{4}{|c|}{ Association analysis $^{b}$} & \multicolumn{2}{|c|}{ Publication Bias } \\
\hline & & Q-test ${ }^{a}$ & 12-test & OR & $95 \% \mathrm{Cl}$ & $\mathbf{P}^{\mathrm{c}}$ & $\mathbf{P}^{\mathrm{d}}$ & Begg $^{e}$ & Egger $^{f}$ \\
\hline \multirow[t]{3}{*}{ RQ vs. RR } & Cervical & & & 0.84 & $0.48-1.48$ & 0.55 & 0.50 & & \\
\hline & Prostate & & & 1.06 & $0.74-1.53$ & 0.74 & & & \\
\hline & Overall & 0.46 & $0.0 \%$ & 0.99 & $0.73-1.35$ & 0.97 & & $\begin{array}{l}\mathrm{T}=-0.33 \\
\mathrm{p}=0.33\end{array}$ & $p=0.59$ \\
\hline \multirow[t]{3}{*}{ QQ vs. RR } & Cervical & & & 0.32 & $0.13-0.74$ & $<0.01$ & $<0.01$ & & \\
\hline & Prostate & & & 2.26 & $1.15-4.44$ & 0.02 & & & \\
\hline & Overall & $<0.01$ & $82 \%$ & 1.06 & $0.63-1.80$ & 0.82 & & $\mathrm{~T}=-0, \mathrm{p}=0.75$ & $p=0.90$ \\
\hline \multirow[t]{3}{*}{$Q Q+R Q$ vs $R R$} & Cervical & & & 0.68 & $0.40-1.18$ & 0.17 & 0.09 & & \\
\hline & Prostate & & & 1.19 & $0.85-1.68$ & 0.31 & & & \\
\hline & Overall & 0.18 & $39 \%$ & 1.02 & $0.76-1.36$ & 0.91 & & $\mathrm{~T}=-0, \mathrm{p}=0.75$ & $p=0.98$ \\
\hline \multirow[t]{3}{*}{$Q Q$ vs. $R Q+R R$} & Cervical & & & 0.35 & $0.16-0.77$ & $<0.01$ & $<0.01$ & & \\
\hline & Prostate & & & 2.18 & $1.12-4.23$ & 0.02 & & & \\
\hline & Overall & $<0.01$ & $82 \%$ & 1.03 & $0.62-1.71$ & 0.92 & & $\mathrm{~T}=-0, \mathrm{p}=0.75$ & $p=0.47$ \\
\hline \multirow[t]{3}{*}{ Q vs R } & Cervical & & & 0.64 & $0.43-0.94$ & 0.02 & $<0.04$ & & \\
\hline & Prostate & & & 1.28 & $0.97-1.68$ & 0.08 & & & \\
\hline & Overall & 0.01 & $74 \%$ & 1.02 & $0.81-1.27$ & 0.89 & & $\mathrm{~T}=0.33, \mathrm{p}=0.33$ & $p=0.59$ \\
\hline \multicolumn{10}{|c|}{${ }^{a} p$-value was calculated by Cochran $\Psi^{2}$-based $Q$ test using RevMan v5.3 } \\
\hline \multicolumn{10}{|c|}{ bSignificant associations are bold } \\
\hline \multicolumn{10}{|c|}{${ }^{\mathrm{C}}$ Test of overall effect } \\
\hline \multicolumn{10}{|c|}{${ }^{\mathrm{d}}$ Comparison between pooled ORs for prostate and cervical cancer, $\mathrm{p}$-value was determined by the $\Psi^{2}$-test } \\
\hline \multicolumn{10}{|c|}{$\begin{array}{l}\text { eBegg-Mazumdar test was used to calculate publication bias. Results are given as Kendall's tau and p-value (any less than } 0.1 \text { was consider significant for publication } \\
\text { bias) }\end{array}$} \\
\hline
\end{tabular}

Table 2: Meta-analysis results for RNASEL R462Q mutation among Latin Americans Cancer subjects.

Three of the studies (one cervical [27] and two prostate cancers [12] were in agreement with Hardy-Weinberg Equilibrium, with one study's p-value equal to 0.05 [28]. 
Citation: Porchia ML, Meda E1, Zepeda RC, Orduña-Salazar AA, Juárez-Salazar G, González-Mejia ME, et al. (2015) Different Effects of the RNASEL R462Q Mutation on the Risk of Developing Prostate and Cervical Cancer in Latin American Subjects: A Meta-Analysis. J Carcinog Mutagen 6: 234. doi:10.4172/2157-2518.1000234

Page 4 of 6

\section{Association of the RNASEL R462Q mutation and developing prostate and cervical cancers}

Overall, this meta-analysis does not suggest an association between the R462Q mutation and the risk for developing cancer among Latin Americans (Figure 2 and Table 2).

A

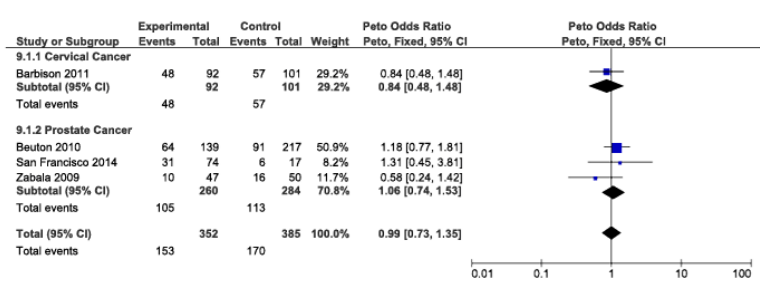

C

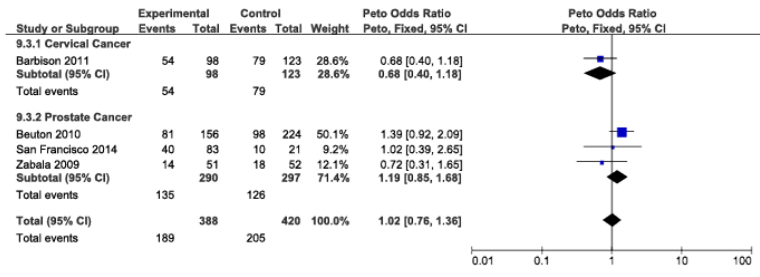

$\mathrm{B}$

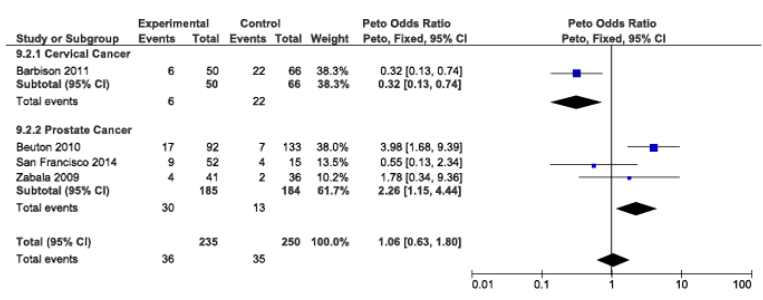

D

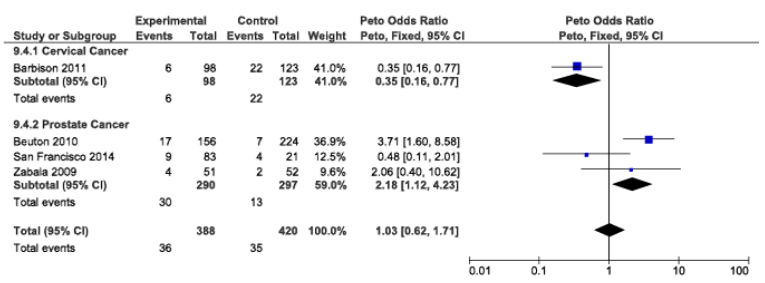

$\mathrm{E}$

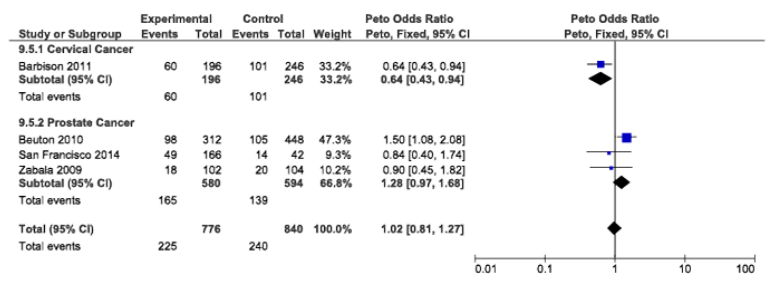

Figure 2: Forest plot of prostate and cervical cancer risk associated with the RNASEL R462Q polymorphism for the heterozygous (A), homozygous (B), dominant (C), recessive (D), and allelic (E) genetic models. The squares and horizontal lines correspond to the studyspecific OR and 95\%CI, respectively. The area of the squares reflects the study-specific weight. The diamond represents the pooled OR and $95 \%$ CI.

However, when stratified by type of cancer, different effects were determined. For cervical cancer, the homozygous, the recessive, and the allelic genetic models all showed a decreased risk of developing cancer $\quad(\mathrm{OR}=0.32,95 \% \mathrm{CI}: 0.13-0.74, \mathrm{p}<0.01, \quad \mathrm{OR}=0.35,95 \% \mathrm{CI}$ : 0.16-0.77, $\mathrm{p}<0.01, \mathrm{OR}=0.64,95 \% \mathrm{CI}: 0.43-0.94, \mathrm{p}<0.05$, respectively). While, for prostate cancers, an increased risk for the homozygous and the recessive genetic models were determined $(\mathrm{OR}=2.26,95 \% \mathrm{CI}$ : $1.15-4.44, \quad \mathrm{p}<0.05$ and $\mathrm{OR}=2.18,95 \% \mathrm{CI}: 1.12-4.23, \quad \mathrm{p}<0.05$, respectively). Furthermore, for the homozygous and allelic genetic model, the increased risk for prostate cancer and decreased risk for cervical cancer were different $(\mathrm{p}<0.01)$. Overall, these results suggest that in male subjects with the recessive homozygote genotype will have an increased risk of developing prostate cancer, whereas for females this genotype is associated with a decreased risk.

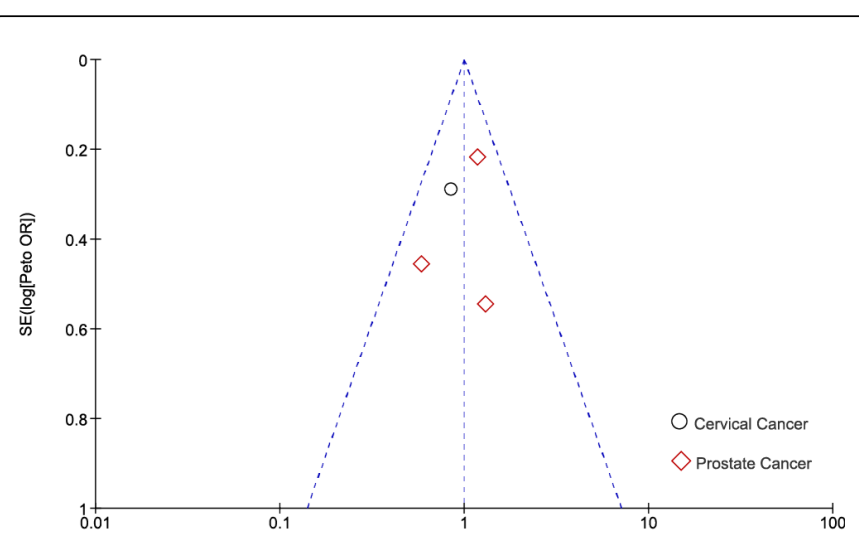

Figure 3: Begg's funnel plot for publication bias test (heterozygous model: RQ vs RR). Each point represents a separate study. 
Citation: Porchia ML, Meda E1, Zepeda RC, Orduña-Salazar AA, Juárez-Salazar G, González-Mejia ME, et al. (2015) Different Effects of the RNASEL R462Q Mutation on the Risk of Developing Prostate and Cervical Cancer in Latin American Subjects: A Meta-Analysis. J Carcinog Mutagen 6: 234. doi:10.4172/2157-2518.1000234

Page 5 of 6

\section{Test for sensitivity and publication bias}

Publication bias was assessed by examining Begg's funnel plot, calculating the Begg-Mazumdar's test Kendall's tau and Egger's test. The funnel plot does not indicate any major asymmetry (Figure 3).

Furthermore, Kendall's tau and Egger's test also does not indicate any significant bias (Table 2).
To assess the sensitivity, one study was removed at a time and the effect on the pooled OR was reevaluated. No significant changes in the pooled OR for all cancers were observed. For prostate cancer alone, due to the small sample size, the homozygous, the recessive, and the allelic genetic models were sensitivity to the Beuten study (Table 3 ).

\begin{tabular}{|c|c|c|c|c|c|c|c|c|c|}
\hline \multirow[b]{3}{*}{ Genetic Model } & \multicolumn{9}{|c|}{ Removed Study } \\
\hline & \multicolumn{3}{|c|}{ Beuten } & \multicolumn{3}{|c|}{ San Francisco } & \multicolumn{3}{|c|}{ Zabala } \\
\hline & OR & $95 \% \mathrm{Cl}$ & P-value & OR & $95 \% \mathrm{Cl}$ & P-Value & OR & $95 \% \mathrm{Cl}$ & P-value \\
\hline$R Q$ vs $R R$ & 0.81 & $0.41-1.61$ & 0.56 & 1.03 & $0.70-1.52$ & 0.86 & 1.20 & $0.81-1.79$ & 0.37 \\
\hline QQ vs $R R$ & 0.92 & $0.31-2.72$ & 0.87 & 3.36 & $1.57-7.20$ & $<0.01$ & 2.37 & $1.13-4.97$ & 0.02 \\
\hline$Q Q+R Q$ vs $R R$ & 0.84 & $0.45-1.56$ & 0.58 & 1.22 & $0.85-1.76$ & 0.29 & 1.32 & $0.91-1.93$ & 0.14 \\
\hline$Q Q$ vs $R Q+R R$ & 0.90 & $0.30-2.66$ & 0.85 & 3.28 & $1.55-6.93$ & $<0.01$ & 2.20 & $1.07-4.55$ & 0.03 \\
\hline Q vs $R$ & 0.87 & $0.52-1.44$ & 0.59 & 1.37 & $1.02-1.84$ & 0.04 & 1.36 & $1.01-1.84$ & 0.04 \\
\hline
\end{tabular}

Table 3: Re-evaluation of pooled Odds Ratio of Prostate cancer studies.

\section{Discussion}

Prostate and cervical cancers are two among the leading forms of cancers for Latin American men and women, respectively. Because these tissues are susceptible to viral infections and viral infections increase the risk of developing cancer, we examined a key regulator of the anti-viral response and pro-apoptotic pathway, namely RNASEL. One mutation, $\mathrm{R} 462 \mathrm{Q}$, has shown diminish protein activity, but its effect on augmenting cancer risk remains inconclusive. This metaanalysis examines the association between the R462Q mutation and risk of developing prostate and cervical cancers.

Four previous meta-analyses have examined the association between the R462Q mutation and prostate cancer, all leading to a similar conclusion that the mutation does not increase the risk of developing prostate cancer in the total population [29-32]. However, these analyses are using mixed samples and only three included the Beuten study. When stratified by ethnicity, the Latin American population was not individually analyzed. Here, we only used studies that focused on Latin American subjects or their descendants. We show that the homozygous mutant genotype is associated with a 2 -fold increased risk of developing prostate cancer. Mi et al. (2010) demonstrated that the homozygous and the recessive genetic models had an increased risk in the total population $(\mathrm{OR}=1.20$-fold, $95 \% \mathrm{CI}$ : 0.96-1.50 and $\mathrm{OR}=1.18,95 \% \mathrm{CI}$ : $0.96-1.46$, respectively) but was not significant [32]. However, the risk increased to 2.50 -fold $(95 \% \mathrm{CI}$ : $1.28-4.87)$ for the homozygous genetic model and 2.54 -fold $(95 \% \mathrm{CI}$ : 1.30-4.95) for the recessive genetic model when examining Africans only (four studies), which is similar to our results. The heterozygous and the dominant genetic models also did not show any increased risk of developing prostate cancer. This meta-analysis supports our results of how one ethnic group can have an increased risk of developing cancer, which is masked by inclusion of the other ethnicities.

Our review of literature only identified two studies that examined the R462Q mutation in cervical cancer: Barbison et al. [27], which focused on women from Argentina, and Madsen et al. [16], which focused on women from Denmark. Using the Madsen et al. data, we determined that the mutation decreased the risk for developing cervical cancer with ORs ranging between 0.35 to 0.65 depending on the genetic model used (data not shown); unfortunately, these data were not significant. For Argentines, Barbison et al. had a similar result, but for the homozygous mutant genotype, it was significant. This would posit the QQ genotype is "protective" as suggest by Madsen et al.; however, due to the lack of numerous studies, this potential effect of the R462Q mutation should be examined cautiously. More studies are required to support this conclusion among many different ethnicities.

Our study has at least four limitations. First, the ORs that were calculated by the genotype distributions and were unadjusted estimates. Adjusting the OR for age, prostate-specific antigen, etc., can influence the OR by a few tenths, possibly affecting the significances of our results. Second, we had limited number of studies to use. However, we selected to use the Peto method, which should minimize this effect. Third, the selection of the controls between studies were slightly different. We chose to include studies in which the controls had prostate-specific antigens levels were less than $4 \mathrm{ng} / \mathrm{mL}$ and a normal digit rectal examine. Lastly, we did not distinguish between severities of the case, by Gleason score, localized versus advanced stage, etc. It is possible that the homozygous mutation genotype is more associated with different forms of either prostate or cervical cancer.

\section{Conclusion}

Here, we compile evidence to support the notion of the dual nature of the RNASEL R462Q mutation in the Latin Americans. We determined that the RNASEL R462Q mutation increases the risk of developing prostate cancer among Latin American men. Interestingly, this mutation is conceivably favorable for Latin American women decreasing the risk of developing cervical cancer.

\section{Acknowledgment}

The authors acknowledge the financial support of Conacyt, project 221196. We would like to express our gratitude to Mtro. Ricardo 
Citation: Porchia ML, Meda E1, Zepeda RC, Orduña-Salazar AA, Juárez-Salazar G, González-Mejia ME, et al. (2015) Different Effects of the RNASEL R462Q Mutation on the Risk of Developing Prostate and Cervical Cancer in Latin American Subjects: A Meta-Analysis. J Carcinog Mutagen 6: 234. doi:10.4172/2157-2518.1000234

Page 6 of 6

Villegas-Tovar, from BUAP Libraries-Department, for aiding in the literature searches and finding articles.

\section{References}

1. World Health Organization (2015) Cancer mortality and morbidity.

2. American Cancer Society (2012) Cancer Facts \& Figures for Hispancis/ Latinos 2012-2014.

3. Arrossi S, Sankaranarayanan R, Parkin DM (2003) Incidence and mortality of cervical cancer in Latin America. Salud Publica Mex 45 Suppl 3: S306-314.

4. Gilliland FD, Hunt WC, Key CR (1996) Ethnic variation in prostate cancer survival in New Mexico. Cancer Epidemiol Biomarkers Prev 5: 247-251.

5. Moreno-Estrada A, Gignoux CR2, Fernández-López JC3, Zakharia F4, Sikora M4, et al. (2014) Human genetics. The genetics of Mexico recapitulates Native American substructure and affects biomedical traits. Science 344: 1280-1285.

6. Pu YS, Chiang HS, Lin CC, Huang CY, Huang KH, et al. (2004) Changing trends of prostate cancer in Asia. Aging Male 7: 120-132.

7. Näsman A, Attner P, Hammarstedt L, Du J, Eriksson M, et al. (2009) Incidence of human papillomavirus (HPV) positive tonsillar carcinoma in Stockholm, Sweden: an epidemic of viral-induced carcinoma? Int J Cancer 125: 362-366.

8. Marur S, D'Souza G, Westra WH, Forastiere AA (2010) HPV-associated head and neck cancer: a virus-related cancer epidemic. Lancet Oncol 11: 781-789.

9. Schlaberg R, Choe DJ, Brown KR, Thaker HM, Singh IR (2009) XMRV is present in malignant prostatic epithelium and is associated with prostate cancer, especially high-grade tumors. Proc Natl Acad Sci 106: 16351-16356.

10. Lunn RM, Bell DA, Mohler JL, Taylor JA (1999) Prostate cancer risk and polymorphism in 17 hydroxylase (CYP17) and steroid reductase (SRD5A2). Carcinogenesis 20: 1727-1731.

11. Meyer MS, Penney KL, Stark JR, Schumacher FR, Sesso HD, et al. (2010) Genetic variation in RNASEL associated with prostate cancer risk and progression. Carcinogenesis 31: 1597-1603.

12. San Francisco IF, Rojas PA, Torres-Estay V, Smalley S, Cerda-Infante J, et al. (2014) Association of RNASEL and 8q24 variants with the presence and aggressiveness of hereditary and sporadic prostate cancer in a Hispanic population. J Cell Mol Med 18: 125-133.

13. Carpten J, Nupponen N, Isaacs S, Sood R, Robbins C, et al. (2002) Germline mutations in the ribonuclease $\mathrm{L}$ gene in families showing linkage with HPC1. Nat Genet 30: 181-184.

14. Lengyel P (1993) Tumor-suppressor genes: news about the interferon connection. Proc Natl Acad Sci U S A 90: 5893-5895.

15. Nakazato H, Suzuki K, Matsui H, Ohtake N, Nakata S, et al. (2003) Role of genetic polymorphisms of the RNASEL gene on familial prostate cancer risk in a Japanese population. Br J Cancer 89: 691-696.

16. Madsen BE, Ramos EM, Boulard M, Duda K, Overgaard J, et al. (2008) Germline mutation in RNASEL predicts increased risk of head and neck, uterine cervix and breast cancer. PLoS One 3: e2492.
17. Xiang Y, Wang Z, Murakami J, Plummer S, Klein EA, et al. (2003) Effects of RNase L mutations associated with prostate cancer on apoptosis induced by 2',5'-oligoadenylates. Cancer Res 63: 6795-6801.

18. Casey G, Neville PJ, Plummer SJ, Xiang Y, Krumroy LM, et al. (2002) RNASEL Arg 462 Gln variant is implicated in up to $13 \%$ of prostate cancer cases. Nat Genet 32: 581-583.

19. Wiklund F, Jonsson BA, Brookes AJ, Strömqvist L, Adolfsson J, et al. (2004) Genetic analysis of the RNASEL gene in hereditary, familial, and sporadic prostate cancer. Clin Cancer Res 10: 7150-7156.

20. Maier C, Haeusler J, Herkommer K, Vesovic Z, Hoegel J, et al. (2005) Mutation screening and association study of RNASEL as a prostate cancer susceptibility gene. Br J Cancer 92: 1159-1164.

21. Rökman A, Ikonen T, Seppälä EH, Nupponen N, Autio V, et al. (2002) Germline alterations of the RNASEL gene, a candidate HPC1 gene at 1q25, in patients and families with prostate cancer. Am J Hum Genet 70: 1299-1304.

22. Rennert H, Zeigler-Johnson CM, Addya K, Finley MJ, Walker AH, et al. (2005) Association of susceptibility alleles in ELAC2/HPC2, RNASEL/ HPC1, and MSR1 with prostate cancer severity in European American and African American men. Cancer Epidemiol Biomarkers Prev 14: 949-957.

23. Kral M, Rosinska V, Student V, Grepl M, Hrabec M, et al. (2011) Genetic determinants of prostate cancer: a review. Biomed Pap Med Fac Univ Palacky Olomouc Czech Repub 155: 3-9.

24. Yusuf S, Peto R, Lewis J, Collins R, Sleight P (1985) Beta blockade during and after myocardial infarction: an overview of the randomized trials. Prog Cardiovasc Dis 27: 335-371.

25. Egger M, Davey Smith G, Schneider M, Minder C (1997) Bias in metaanalysis detected by a simple, graphical test. BMJ 315: 629-634.

26. Begg CB, Mazumdar M (1994) Operating characteristics of a rank correlation test for publication bias. Biometrics 50: 1088-1101.

27. Barbisan G, Contreras A, Pérez LO, Difranza L, Golijow CD (2011) The effect of TP53 codon 72 and RNASEL codon 462 polymorphisms on the development of cervical cancer in Argentine women. Cancer Genet 204: 270-277.

28. Beuten J, Gelfond JA, Franke JL, Shook S, Johnson-Pais TL, et al. (2010) Single and multivariate associations of MSR1, ELAC2, and RNASEL with prostate cancer in an ethnic diverse cohort of men. Cancer Epidemiol Biomarkers Prev 19: 588-599.

29. Li H1, Tai BC (2006) RNASEL gene polymorphisms and the risk of prostate cancer: a meta-analysis. Clin Cancer Res 12: 5713-5719.

30. Wei B, Xu Z, Ruan J, Zhu M, Jin K, et al. (2012) RNASEL Asp541Glu and Arg462Gln polymorphisms in prostate cancer risk: evidences from a meta-analysis. Mol Biol Rep 39: 2347-2353.

31. Mi YY, Zhu LJ, Wu S, Feng NH (2011) An update analysis of two polymorphisms in encoding ribonuclease $\mathrm{L}$ gene and prostate cancer risk: involving 13,372 cases and 11,953 controls. Genes Nutr 6: 397-402.

32. Mi Y, Yu Q, Min Z, Xu B, Zhang L, et al. (2010) Arg462Gln and Asp541Glu polymorphisms in ribonuclease $\mathrm{L}$ and prostate cancer risk: a meta-analysis. J Biomed Res 24: 365-373. 